\title{
Spatial Analysis for Flood Control by Using Environmental Modeling
}

\author{
Alireza Gharagozlou*, Hassan Nazari, Mohammadjavad Seddighi \\ Geomatics College of National Cartographic Center of Iran (NCC), Tehran, Iran \\ E-mail: *agharagozlu@yahoo.com \\ Received June 22, 2011; revised July 25, 2011; accepted August 6, 2011
}

\begin{abstract}
To create the final spatial information and analysis, flood hazard maps and land development priority maps and information, data for the flood events to 2009 in north of Iran were incorporated with using Geo-spatial Information System data of physiographic divisions, geologic divisions, land cover classification, elevation, drainage network, administrative districts and population density and environmental parameters modeling. Special analysis also attention was paid to population density for the construction of the land development priority map and using satellite image analysis to determine land use changes and analysis of geo-spatial information, because highly dense populated areas represent the highly important urban and industrial areas. While geo-information technology offers an opportunity to support flood management adequate geo-spatial information is a prerequisite for sustainable development, but many parts of the world lack adequate information on environmental resources. Such information providing, which serves as an important tool for decision-making in land use planning, can help provide effective information to natural disaster management. This paper develops a framework for flood control and begins with some general comments on the importance of land use planning and outlines some current environmental issues and then presenting environmental models to use in disaster management plan by using GIS and remote sensing results. Flood control is a complex problem that requires cooperation of many scientists in different fields. The article also discusses the role that geo-information and environmental planning and GIS and remote sensing technology play in disaster management control to reduce negative impacts of flood and present proper alternatives for developing of Gorganrood in the north of Iran. Advanced high-resolution sensor technology has provided immense scope to the decision makers for analysis of flood and damages details using GIS and remote sensing.
\end{abstract}

Keywords: Environmental Modeling, Land Use Planning, Geo-Spatial Information, GIS

\section{Introduction}

This article begins with some general comments on the importance of land use planning and outlines some current environmental issues. It also highlights the connection between land use planning and sustainable development and the discussion describes several key methods of resource identification, with particular emphasis on existing potential of geo-information technology that offers an opportunity to support disaster management: floods and environmental impacts assessment and natural disaster in national level. The article also discusses the role of geo-information data in promoting geographic information system use. By attention to natural disasters in Iran especially flood in Golestan in the North of Iran proper assessment of flood by using environmental de- velopment models and GIS and with attention to Sustainable development approach and disaster management are presented. The article offers proposed models that illustrate how GIS and remote sensing data can be used in land use planning programs that take a sustainable development approach [1] and disaster management (flood). Excessive land use and increased human impacts have imposed significant pressures on the environment worldwide. These effects are increasingly noticeable from a scientific and technical viewpoint. Future development should proceed on the basis of proper land use planning, with minimum destruction of the environment because impacts of human activities results natural disasters in some area [2]. Planning assessments must therefore consider environmental issues and natural disaster (flood) and use environmental and geo- 
referenced information to refine decisions. Gathering information reveals the available potential of the environment; development planning at the nationwide level can help decision-makers identify resources and target their future scientific studies to reach sustainable development.

Moreover, each minute, 5.6 hectares of forest are being destroyed and some other human activities cause disaster such as flood in some parts of the world.

\section{Materials and Methods}

Floods are one of the most common hazards in the world also in the some parts of north of Iran. Flood effects can be local, impacting a neighborhood or community, or very large, affecting entire river basins and multiple states [3]. However, all floods are not alike. Floods themselves average four billion dollars annually in property damage alone. Some floods develop slowly, sometimes over a period of days. But flash floods can develop quickly, sometimes in just a few minutes and without any visible signs of rain. Flash floods often have a dangerous wall of roaring water that carries rocks, mud, and other debris and can sweep away most things in its path. Overland flooding occurs outside a defined river or stream, such as when a levee is breached, but still can be destructive. Some general reasons of flood include: weather related reasons: heavy rainfall, duration of precipitation, sudden snow melting and physical conditions: soil variety, slop of lands, land degradation and human activities: deforestation, misusing of land and transforming to grasslands or agricultural area, misconstruction of roads, bridges, dams and environmental situations. Flooding can also occur when a dam breaks, producing effects similar to flash floods. Be aware of flood hazards no matter where you live, but especially if you live in a low-lying area, near water or downstream from a dam. Even very small streams, gullies, creeks, culverts, dry streambeds, or low-lying ground that appear harmless in dry weather can flood every state is at risk from this hazard [4]. Some scientists think the major problem about natural disaster and flood is in the improper exploitation of land [5]. By using process of plan compilation with a land use planning approach some important negative impacts that cause flood is under our control.

\subsection{Identification of Land Resources for Planning}

Statistics and sampling, conversion of the aerial photos, satellite images and topographic maps, automatic conversion of aerial photos and satellite images and data of remote sensing, geographic information systems are dif- ferent methods of identification of resources. One of the objectives of this study is to utilize GIS data to construct a set of GIS data, a flood hazard map, and land development priority map to help the responsible authorities develop, design and operate flood control infrastructure and prepared aid and relief operations for high-risk areas during future floods. In recent years the combination of 3D-laser scanning and side-scan can be very beneficial for mapping complicated water side areas; the two systems are complementary [6]. To geo-reference the relative location, GPS positioning required.

It should be clear that presenting an environmental development model to be used in a GIS for natural disaster management has a lot of restrictions and limitations [7] whose description would lead too far here. Some factors that have been considered in presenting the model include; industrial sites, transportation networks, weather and climate data, landform, elevation, slop, geology, bedrock, soil, water resources, vegetation, installations and buildings, energy transmission stations, natural resources, gardens, forests, parks, etc. the priority of the mentioned parameters are different in the model[8]. It is clear that north of Iran and Golestan has an environmental development context and is under the interactive effects of the large region. Also it is thus impossible to correctly analyze the environmental conditions for natural disaster management without considering the social and economic activities in this district.

\section{Modeling}

Environmental modeling is a complex problem that requires cooperation of many scientists in different areas. In this paper, the architecture and results of environmental modeling and using satellite image processing and GIS for Flood control is presented. Set out below are mathematical linear models for flood management in Golestan. Flood inundation modeling requires distributed model predictions to inform major decisions relating to planning [9]. Present flood model integrates GIS with the environmental modeling and greatest daily of precipitation from1995 to 2009 to determine improper area for development. A linear mathematical model for flood management has been Introduced because proper planning based on environmental potentials cause reduce risk potentials of flood in future and this linear model with attention to planning results sufficient for development impacts on disaster. FF refer to specific model with environmental planning approach for flood management and attention proper land use planning in the region that present location of improper area for development. Predicting the river's flood is one of the important factors for design of dams and hydraulic structures and regional 
and urban development planning. As geo-information data also used in flood management, many problems occur in flood estimation. One of the methods for plan- ning is determination improper area for development by environmental modeling, statistics and using GIS/RS technology [10].

$$
\begin{gathered}
R=S(4,5,6,7,8)+A S(1,2,3,7,8)+H(1,2,3,4)+B((x, y)>R R) \\
R R=R 1(V 1+M 1)+R 2(V 2+M 2)+R 3(V 3+M 3)+\ldots F F=S(5,6)+H(5,6)+Q A(2,3,4)+M A(1,2,3) \\
+W S(5,6)+S O(1,2,4,5,6)+S W(1,2,3)+N I(1,2,3)+H P(1,2,3)+H B U(1,2,3)+H B R(1,2) \\
+S o(3,4,5,7,8,9,10,11)+S d(4,5)+\operatorname{Prc}(1,2)
\end{gathered}
$$

where:

$S$ is slope, $H$ is height or altitude, $A$ is aspect, $Q A$ is fault line, $M A$ is distance from ravine areas, $W S$ is wind speed, $S O$ is soil components, $S W$ is distance from subterranean water resources, $N I$ is distance from industrial sites and $H P$ is historical landmark, $H B U$ is Distance from urban habitat and $H B R$ is distance from rural habitat and Lo, $\mathrm{Ma}(\mathrm{R}-\mathrm{year})$ is the maximum precipitation based on geographical location. For purposes of the linear models, the terms used have the following definitions: "Slope" $(S)$ includes six classes: 0 to $2 \%$ (class 1 ), 2 to 5\% (class 2), 5 to 8\% (class 3), 8 to 12\% (class 4), 12 to $15 \%$ (class 5 ), and more than $15 \%$ (class 6$)$. "Height” $(H)$ includes six altitude classes: less than 1000 meters (class 1), 1000 - 1200 meters (class 2), 1200 - 1400 meters (class 3), 1400 - 1600 meters (class 4), 1600 - 1800 meters (class 5), and more than 1800 meters (class 6). "Distance from ravine areas” (MA) includes four classes: less than 50 meters (class 1), 50 - 300 meters (class 2), 300 500 meters (class 3), and more than 500 meters (class 4). "Subterranean water resources" (SW) divides resources into four classes, based on distance to the water resource: less than 100 meters (class 1), 100 - 500 meters (class 2), 500 - 1000 meters (class 3), and more than one kilometer (class 4). "Distance from industrial sites" (NI) includes three classes: less than 5 kilometers (class 1), 5 - 10 kilometers (class 2), and 10 - 20 kilometers (class 3). "Distance from Urban Habitat" (HBU) divides 4 four classes: less than 5 kilometers (class 1 ), between 5 to 10 kilometers ( class 2), between 10 - 20 kilometers (class 3) and more than 20 kilometers (class 4), "Historical landmark" (HP) divides historical places into four classes, based on how far away they are located: less than 5 kilometers (class 1), 5 - 10 kilometers (class 2), 10 - 20 kilometers (class 3), and more than 20 kilometers (class 4), Distance from rural habitat "HBR" divides rural area and around this to 4 classes: less than 2 kilometers (class 1), 2 - 4 kilometers (class 2), 4 - 8 kilometers (class 3) and more than 8 kilometers class 4 and Prc is precipitation in $\mathrm{mm}$ in 7 classes more than 2000, 1800 - 2000, 1200 - 1800, 800 - 1200, 500 - 800, 200 - 500, 50 - 200 and less than $200 \mathrm{~mm}$ and So is soil construction in 11 classes and $S d$ is soil depth in 5 classes include more than 180, 120 - 180, 60 - 120, 30 - 60, less

than $30 \mathrm{~cm}$.

With attention to linear model of flood control and data analysis and using GIS the result of analysis are as maps presented that are presented in Figures 1-4.

Satellite data also can be effectively used for mapping and monitoring the flood inundated areas, flood damage assessment, flood hazard zoning and post-flood survey of rivers configuration and protection works. Analyzing the satellite images reveal a noticeable reduction of forestlands in north of Iran due to the expansion of the urban limits misuse from these area. The other fixed natural resources of the region too have been overused resulting in environmental destruction of the area. The amount of residential areas during 1995 and 2009 show an 8\% growth while there is no increase in the number of forestlands. There are several definitions of sustainability in the urban forestry sector that we attention in this paper based on analysis results and conditions in urban area. The amount of forestlands declined about 1 hectare every year and open areas have been reduced thus leading to the conclusion that most of the construction activity took place in forestlands and results suiting with other experiences in this filed.

\section{Conclusions}

In this paper Innovations in the filed of environmental modeling which are based on natural disaster management for flood in Iran and using proper models for analysis in GIS are presented.

Geo-information technology offers an opportunity to support disaster management and floods as the natural disaster management. Gorganrood rivers waterways trails as a pedestrian pass with a stream of spring and rain which also can hold heavy rain water as a flood control waterway. One of the obvious and prominent aspectsof innovations in this paper, are the models that can integrate between Geo-information technology and environmental modeling and natural disaster management. Analysis positioning of improper locations by using 
GIS/RS technology for development area determination based on the environmental capacities with a flood control approach.

At the same time, by using GIS necessary analysis to find flood risk in the region and impacts of flood on natural and human facilities are presented. Choosing proper linear models based on environmental capacity with a flood management emphasize determining the ecological potentials of the area and using GIS is the important point of this paper. The joint application of GIS and environmental modeling and using remote sensing technology can help land use planners apply op-

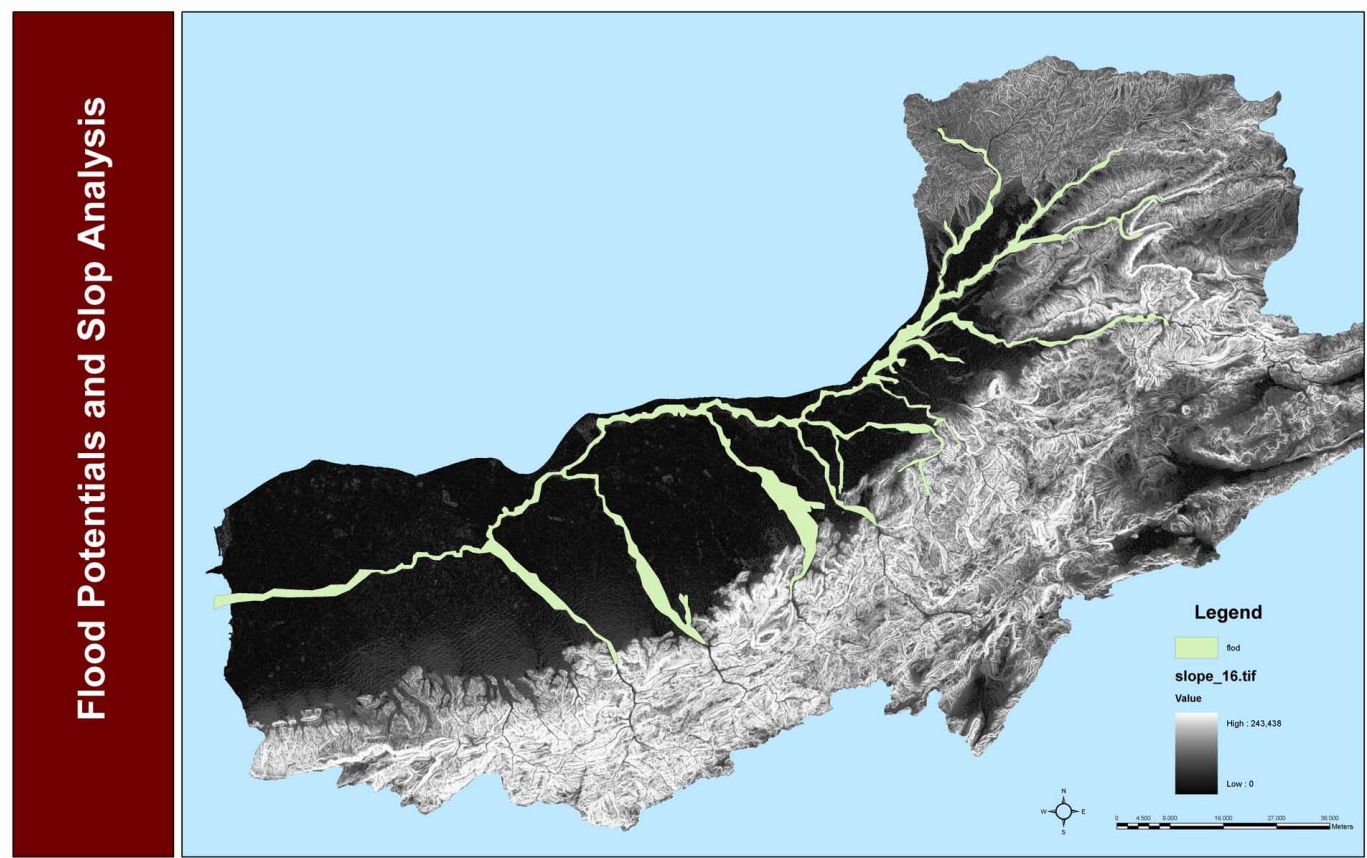

Figure 1. Spatial Analysis for determination flood risk area and improper area for development using flood modeling in north of Iran.
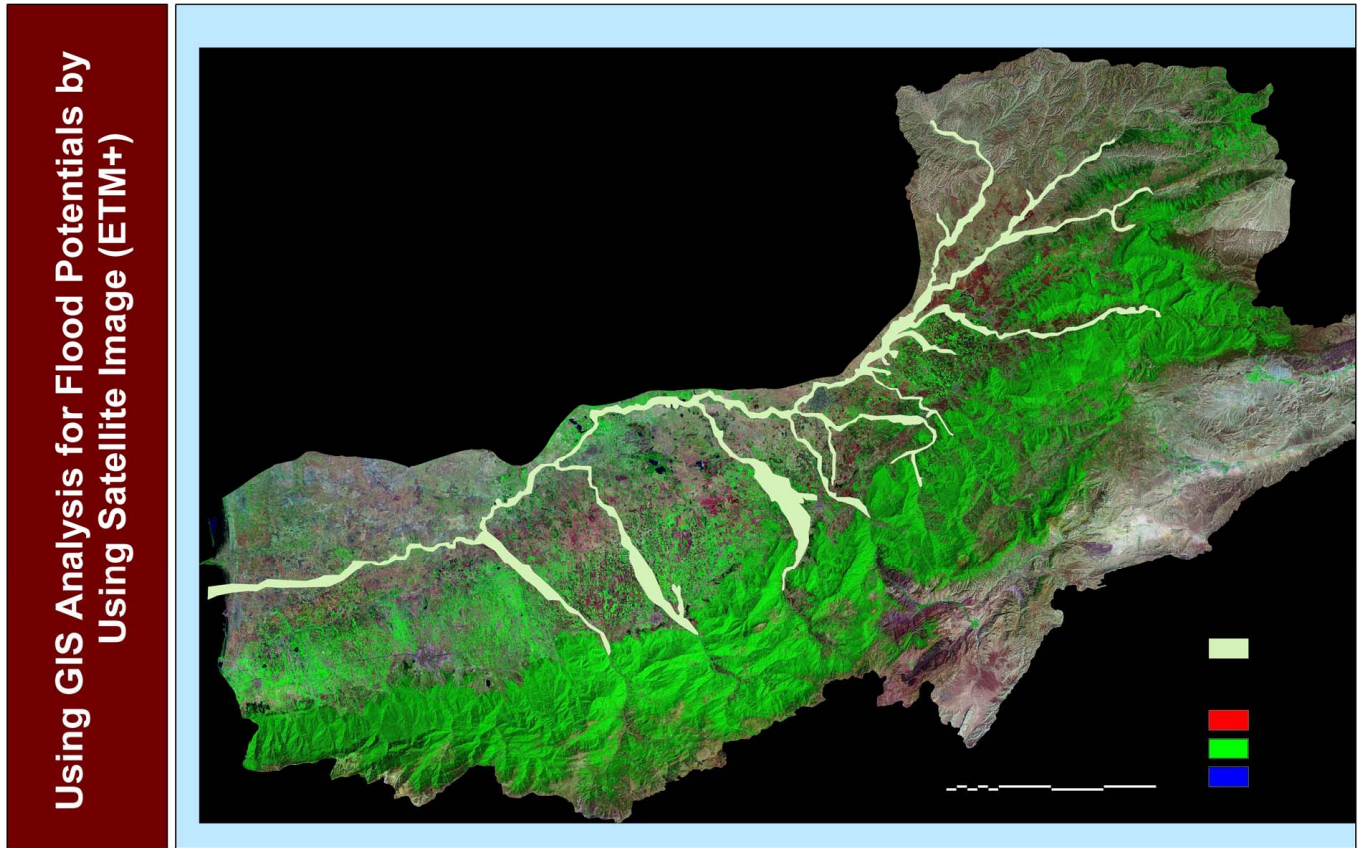

Figure 2. Satellite image processing (ETM+) in Golestan, Gorganrood, and risk assessment and modeling for flood control. 


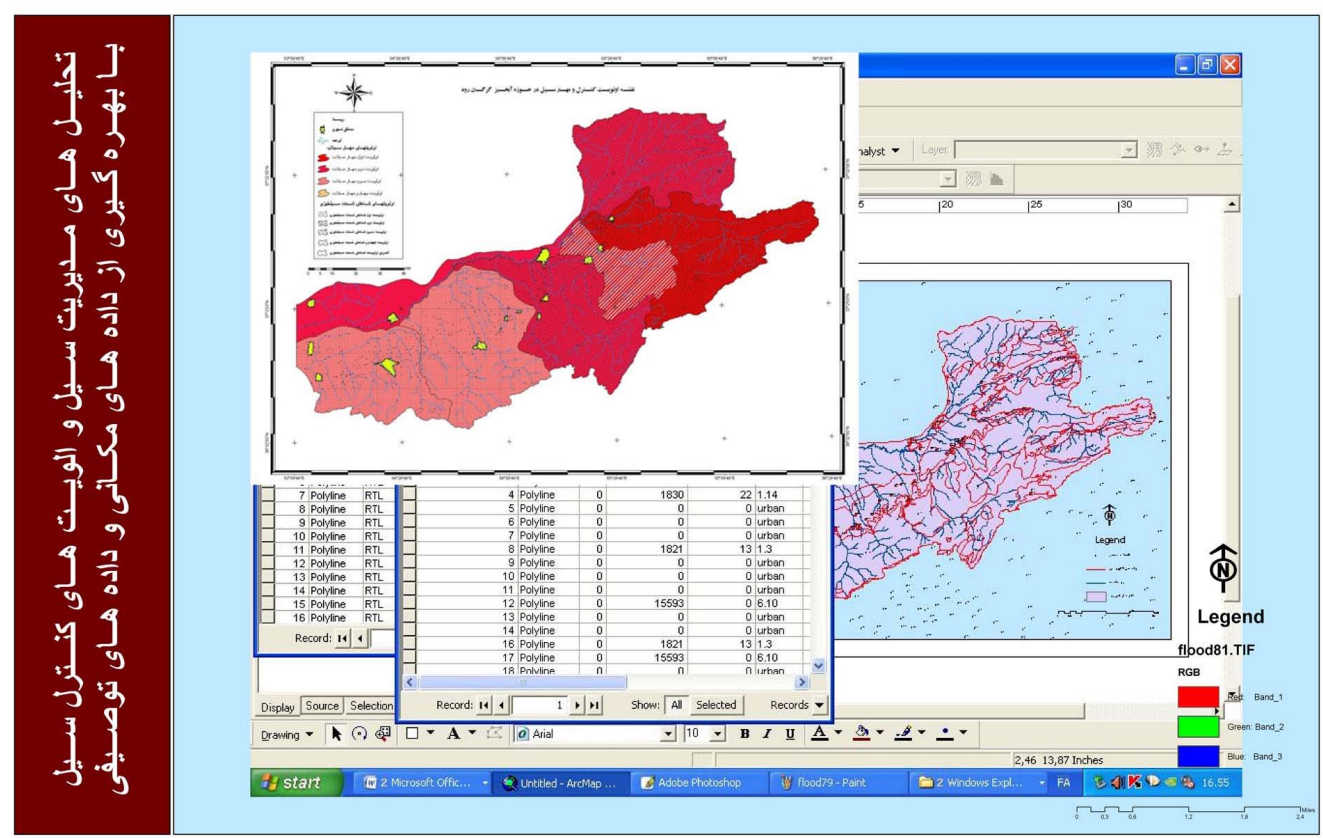

Figure 3. Districts risk classification for flood control by using GIS.

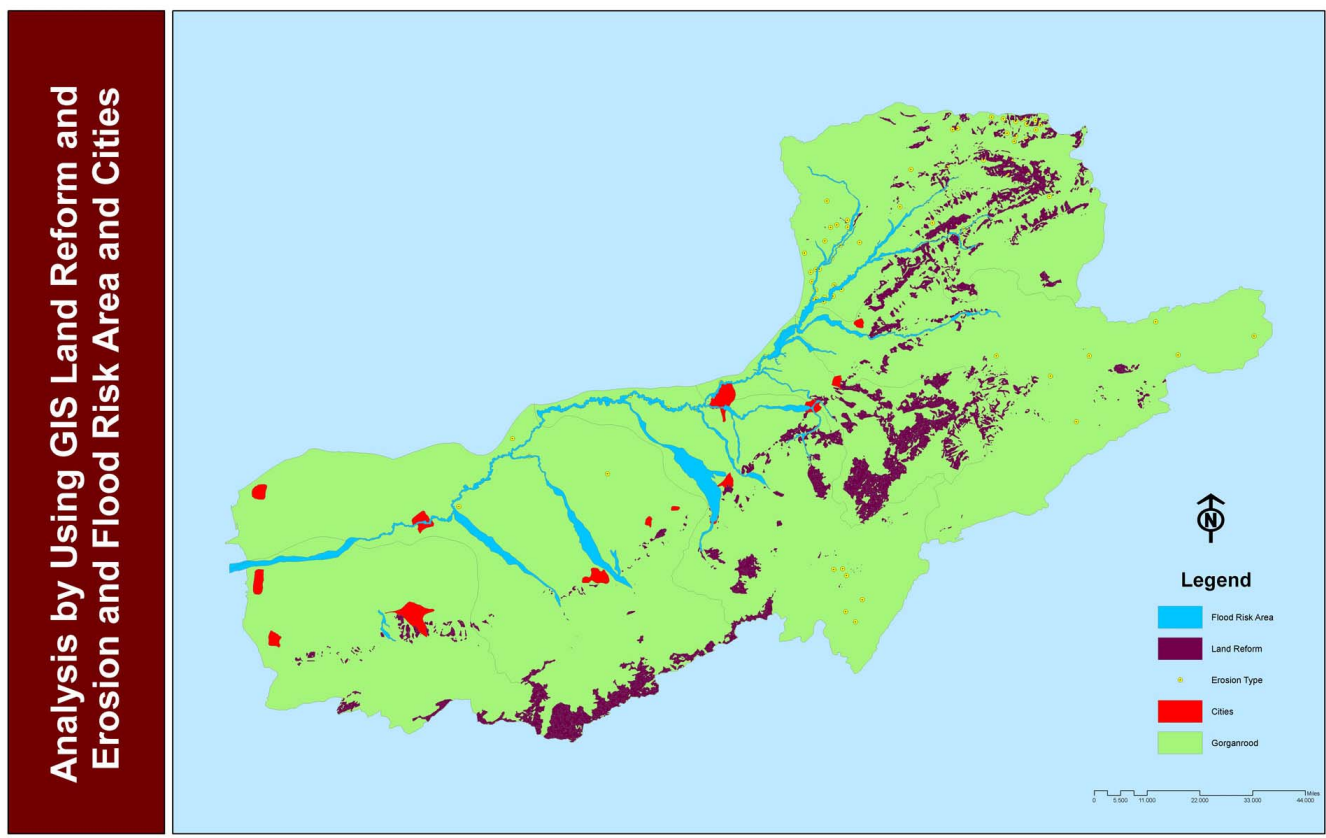

Figure 4. Land reform and erosion and cities under flood risk.

timal development planning guidelines. The other key idea we suggest here is the need to compare the results of these analyses with future development plans. Comparing the natural potential of the territory with predicted development plans can result in better decision making to reduce the cost of flood in rural and urban area. The use of GIS technique during the last decade are increasing being applied for identification of natural resources but the practice of analyzing the development models with the use of GIS/RS in development planning for flood management is a new experience.

\section{References}

[1] J. Hardisty, D. M. Taylora and S. E. Metcalf, “Computerized Environmental Modeling: A Practical Introduction 
Using Excel,” Wiley, New York, 1993, pp. 80-88.

[2] A. Gharagozlou, "Crisis Management (Flood) and GIS," Geomatics College of NCC of Iran, Tehran, 2010, pp. 2329.

[3] S. Andera, "Geo-Information for Disaster Management," GIM International, Amsterdam, 2005, pp. 10-12.

[4] A. Gharagozlou, "Environmental Planning for Natural Disaster by Using GIS,” International Society for Photogrammetry and Remote Sensing, 2007.

[5] E. Wolk and B. Zagajewski, "Remote Sensing of Environment Laboratory, Faculty of Geography and Regional Studies,” University of Warsaw, Warsaw, 1999, pp. 4457.

[6] J. Fairley, "Environmental Planning," Department of Environmental Planning, University of Stratchlyde, Stra- tchlyde, 2001, pp. 111

[7] S. kimitrero, "Flood Hazard Assessment for the Constructionof Flood Hazard Map and Land Development Priority Map Using NOAA/AVHRR DATA,” GIS Development Journal, Vol. 4, 2006, pp. 3-12.

[8] Heywood LAN, S, Cornelius and S. Carver, "Cornelius; An Introduction to Geographic Information Systems," chap., 1998, pp. 2-5.

[9] K. Clayton, "The Land Form Space, Environmental Science for Environmental Management,” Longman, London, 1990, pp. 198-222.

[10] F. Ferrini, "Sustainable management techniques for trees in the urban area, Journal of Biodiversity and Ecological Sciences,” IAU University, Tonekabon, 2010, pp. 1-19.

\section{Appendix}

Important information about greatest daily of precipitation in Gorganrood in the north of Iran and monthly precipitation and days with and without snow according to statistics of metrological organization of Iran are used for GIS analysis. Some factors include:

- GREATEST DAILY OF PRECIPITATION IN MM

- MONTHLY TOTAL OF PRECIPITAION IN MM

- NO OF DAYS WITH PRECIPITATION

- NO OF DAYS WITH PRECIPITATION EQUAL TO OR GREATER THAN 1 MM

- NO OF DAYS WITH PRECIPITATION EQUAL TO OR GREATER THAN 5 MM

- NO OF DAYS WITH PRECIPITATION EQUAL TO OR GREATER THAN 10 MM

- NO OF DAYS WITH SNOW OR SLEET

VISIBILITY WIND CLOUDY SUNSHINE DEGREE DAYS TEMPERATURE HUMIDITY PRESSURE PRECIPITATION

- HOUR MAXIMUM PRECIPITATION

- MONTHLY TOTAL PRECIPITAION WITH SEASONAL PERCENT

- NO OF DAYS WITH PRECIPITATION

- NO OF DAYS PRECIPITATION EQUAL OR MORE THAN 1 MM

- NO OF DAYS PRECIPITATION EQUAL OR MORE THAN 5 MM 